\title{
RECLUSÃO FEMININA: AS IMPLICAÇÕES DA VISITA ÍNTIMA NA ADAPTAÇÃO À PRISÃO
}

\section{Resumo}

O objetivo deste estudo é compreender a adaptação à prisão de reclusas e analisar as suas atitudes e perceções sobre a influência das visitas íntimas neste processo. Para tal, realizámos entrevistas a quarenta reclusas detidas num estabelecimento prisional feminino (vinte inscritas e vinte não inscritas no Regime de Visitas Íntimas). Com recurso à análise de conteúdo categorial das entrevistas, concluímos que a maioria das mulheres passou por um período psicologicamente conturbado, sendo a maior causa de dores de prisão o afastamento da família e dos filhos. Como consequência, estas mulheres percecionam as visitas íntimas como um programa significativo e benéfico na medida em que atenua as dores de prisão.

Palavras-chave: Reclusão feminina, visitas íntimas, adaptação à prisão, atitudes, perceções.

\section{Abstract}

\section{Female Incarceration: Implications of the intimate visits on prison adaptation}

This study aims to understand female prisoners' adaptation to the imprisonment and to analyze their attitudes and perceptions about the influence of intimate visits in this process. To this end, we conducted interviews with forty female inmates (twenty registered and twenty not registered in the Intimate Visit Scheme). Through content analysis of the interviews conducted, we conclude that most of the women went through a psychologically troubled period, and their biggest prison pain was the removal from family and children. As a result, these women perceive intimate visits as a meaningful and beneficial program as it reduces prison pains. tions.

Keywords: Female incarceration, intimate visits, prison adaptation, attitudes, percep-

\section{Résumé}

Réclusion féminine: les implications de la visite intime à l'adaptation en prison

Nous avons mené des entretiens avec quarante détenues (vingt détenues inscrites et vingt non enregistrées dans le cadre du programme de visites intimes). Par l'analyse du contenu des entretiens menés, nous concluons que la plupart des femmes ont vécu une période psychologiquement troublée et que leur plus grande souffrance en prison est l'éloignement de la famille et des enfants. En conséquence, ces femmes perçoivent les visites

Faculdade de Psicologia e Ciências da Educação da Universidade do Porto (FPCEUP).

Endereço postal: FPCEUP, Rua Alfredo Allen 4200-135 Porto, Portugal.

Endereço eletrónico: psi.ritapinto@gmail.com

ORCID: https://orcid.org/0000-0001-7915-1503

Endereço eletrónico: oliveira@fpce.up.pt

ORCID: https://orcid.org/0000-0002-8453-1719 
intimes comme un programme bénéfique car il atténue les souffrances de l'emprisonnement.

Mots-clés: Incarcération de femmes, visites intimes, adaptation aux prisons, attitudes, perceptions.

\section{Introdução}

As teorias criminais raramente se preocuparam com a análise da criminalidade feminina (Smart 2008), sendo no contexto da criminologia positivista do século XIX que surgiu o estudo da delinquência feminina, depois de uma longa ausência das mulheres nas investigações (Matos 2008). Apesar desta inclusão e da evolução observada durante mais de um século, a menor referência ao crime no feminino, tradicional na criminologia, traduziu-se também em Portugal na ausência, durante décadas, de estudos sobre a mulher que transgride (Matos e Machado 2007). Embora ainda se considere que o estudo do crime continua a privilegiar o universo masculino (Duarte e Gomes 2015), tal vem a ser colmatado, nomeadamente em Portugal, por um conjunto de estudos conduzidos por diversas autoras (e.g., Cunha 1994, 2002; Matos 2008; Duarte e Gomes 2015; Granja 2017).

No que respeita, especificamente, à sexualidade na prisão, este é um tema controverso, que chama pouco a atenção dos cientistas sociais (Cordeiro 2017). Ainda assim, a este respeito, em Portugal, podemos citar a dissertação de mestrado de Sara Melo (2013), que aflora a forma como os homens reclusos experienciam e atribuem sentido às visitas íntimas, bem como a de Ricardo Silva (2016), que - não se focando nas visitas íntimas, mas na forma como os reclusos percecionam as relações sexuais entre homens na prisão - encontra em todos os entrevistados o desejo de ter visitas íntimas para realçar a falta de relações sexuais com uma mulher. No entanto, o maior destaque deve ser dado ao trabalho de Rafaela Granja (2017) que, tendo como tema central as relações familiares na interface entre o interior e o exterior da prisão, apresenta alguns dados relativos às experiências e representações das reclusas sobre o Regime de Visita Íntima. Por sua vez, a investigação científica sobre a adaptação à reclusão também se centra maioritariamente nos homens reclusos, sendo escassos os estudos que escolhem abordar este tema a partir de amostras com reclusas. Com o aumento do número de mulheres ofensoras, identificar como se processa a sua adaptação à vida na prisão torna-se cada vez mais importante, tendo em vista a melhoria do ambiente correcional e sendo a reabilitação o objetivo último.

A reclusão, ao exigir a modificação radical de padrões de vida e de funcionamento básico de um indivíduo, torna-se, não raras vezes, uma experiência stressante (Bender 2015). Como defendem Steiner e Wooldredge (2009), as experiências e atividades durante a reclusão são uma das principais categorias preditoras do desajuste que pode funcionar como mecanismo de controlo do comportamento 
do/a recluso/a, tanto de forma direta como indireta. Assim, neste artigo, iremos focar-nos na visita íntima, que é uma das experiências possíveis de serem vivenciadas durante o período de reclusão, tentando compreender em que medida esta se relaciona com o processo de adaptação ao meio prisional.

Desde o início dos estudos sobre o tema das visitas íntimas, os defensores destes programas têm argumentado que estas mantêm a estabilidade familiar (Cordeiro 2017; Turanovic e Tasca, 2019), reduzem o comportamento violento sexual e não sexual na prisão (D’Alessio, Flexon e Stolzenberg 2013), diminuem o isolamento social na prisão, aumentando o bem-estar psicológico da pessoa reclusa (De Claire e Dixon 2017), diminuem a probabilidade do indivíduo reincidir (Mears et al. 2012) e promovem uma reinserção social mais positiva (Visher e O'Connell 2012).

De um modo geral, a literatura sugere que a falta de apoio de outras pessoas significativas fora da prisão parece ser bastante crítica para as mulheres que têm dificuldade em adaptar-se ao ambiente institucional (Bender 2015; Kotova 2019) e que o apoio e estabilidade dos membros da família têm efeitos estatisticamente significativos sobre a adaptação à vida na prisão (Chen, Lai e Lin 2014).

$\mathrm{O}$ argumento de que as visitas, no geral, e as visitas íntimas, em particular, reduzem o comportamento violento na prisão deve ser salientado. A literatura sugere que as visitas íntimas, ao permitirem a manutenção dos laços com a família, amigos e membros da comunidade, funcionam como um instrumento de controlo informal, podendo contribuir para desencorajar a má conduta institucional do/a recluso/a (Jiang e Winfree 2006; Turanovic e Tasca 2019).

Estas ligações familiares podem ser importantes num contexto onde a pessoa reclusa enfrenta uma pressão considerável para a conformidade com as subculturas desviantes da prisão, uma vez que, se as conexões com a comunidade enfraquecem, o/a recluso/a pode começar a identificar-se mais com a cultura da prisão (Cochran 2012), dando-se o chamado processo de prisionização. No seu estudo, Cochran (2012) sugere que uma explicação plausível para tal pode ser a de que o contacto regular com amigos e familiares permite que a pessoa mantenha o seu papel na família ou como membro da comunidade, identificando-se em menor grau com a subcultura da prisão. Neste sentido, os estudos apontam que a manutenção de laços sociais parece ser um mecanismo fundamental através do qual as pessoas na prisão podem evitar a influência potencialmente criminógena do período de reclusão (Mears et al. 2012; Granja 2017). Num estudo de 2019, OspinaGómez e Bedoya-Gallego apoiam esta hipótese de que o estado de prisionização, somado a um baixo suporte social, ou mesmo ao abandono dos familiares mais próximos, geram uma série de reações negativas prejudiciais ao bem-estar físico e psicológico da população reclusa.

Como os estudos sobre a adaptação à prisão sugerem, uma das preocupações centrais que os/as reclusos/as expressam é o isolamento das redes sociais às quais pertenciam e nas quais participaram anteriormente (Mears et al. 2012). Assim, a 
visita pode reduzir os sentimentos de perda e frustração e a falta de esperança associados à quebra dos laços com a família, amigos e comunidade.

Neste artigo, os objetivos envolviam compreender o modo como as reclusas vivenciam o processo de adaptação à reclusão, bem como identificar e analisar as atitudes e as perceções das reclusas, inscritas e não inscritas no Regime de Visitas Íntimas (RVI), acerca da influência na vivência prisional da participação neste regime.

\section{Metodologia}

Tendo em conta que se pretendia aceder aos discursos sobre o RVI e a influência deste na vivência da reclusão feminina, optámos pela entrevista qualitativa semiestruturada como instrumento de recolha de dados, pois esta permite-nos captar o discurso e os significados das participantes.

Uma vez que a investigação existente em Portugal sobre esta temática, dando voz às próprias reclusas inscritas no RVI, é escassa e não se conhece qualquer estudo no nosso país sobre as perceções que as reclusas não inscritas neste regime possuem sobre este, optámos por incluir na nossa amostra mulheres com e sem visita íntima, comparando os resultados dos dois grupos.

O método de seleção da amostra foi aleatório, tendo por base duas listas disponibilizadas pela direção do Estabelecimento Prisional onde foi efetuado o estudo: a primeira, das reclusas inscritas no regime de visitas íntimas (62 mulheres no total, à data das entrevistas) e, a segunda, das restantes reclusas detidas nesse mesmo estabelecimento prisional (278 reclusas sem RVI). A nossa amostra é constituída por 40 reclusas, das quais 20 estavam inscritas no RVI e 20 não usufruíam deste tipo de visitas. Destas 40, três são de nacionalidade estrangeira, sendo a média de idades de 37 anos. Na totalidade da amostra, existem 21 reclusas primárias e 19 reclusas reincidentes, com uma média de três anos de reclusão, estando seis em prisão preventiva e as restantes condenadas, na sua maioria, pelo crime de tráfico de droga. Das reclusas inscritas no RVI, 11 tinham os companheiros presos e, das reclusas sem RVI, 13 não estavam, à data das entrevistas, num relacionamento amoroso.

Foram elaborados dois guiões de entrevista semiestruturada, um para cada grupo de participantes, com e sem RVI, contendo questões que, depois de realizada a devida revisão da literatura, foram consideradas importantes para o cumprimento dos objetivos deste estudo. Cada entrevista abordou três temas: (1) A criminalidade feminina, com questões gerais sobre a prática do(s) crime(s) que originou(aram) a reclusão; (2) A adaptação à reclusão, que incluiu questões que permitissem apreender o modo como cada entrevistada vivenciava a sua reclusão; (3) As Visitas Întimas. 
No início da interação com cada entrevistada foram esclarecidos os objetivos do estudo e o processo de recolha dos dados, bem como as condições em que a entrevista iria ocorrer, com garantia de anonimato. Tendo compreendido as informações prestadas e estando de acordo com a participação na investigação, as reclusas assinavam um consentimento informado, onde constava uma explicação das questões supracitadas e a autorização das próprias para se proceder à gravação áudio dos relatos. As entrevistas decorreram num gabinete privado do estabelecimento prisional, tendo a sua duração variado entre quinze minutos e uma hora e meia.

Para analisar as entrevistas, recorremos à análise de conteúdo categorial de acordo com Bardin (2006), no sentido de retirar o máximo de informação do material recolhido. A análise foi validada por um terceiro independente.

Neste artigo, apresentaremos dois temas identificados na análise do conteúdo das entrevistas: 1) Obstáculos à adaptação à reclusão - que designaremos fazendo uso do conceito de dores de prisão de Sykes ([1958] 2007) - e as estratégias para o seu enfrentamento; e 2) Atitudes, vantagens e desvantagens do RVI. De modo a atribuir uma identificação aos excertos, mantendo a confidencialidade, optamos por codificá-los, sendo que do R1 ao R20 constam expressões retiradas das entrevistas às reclusas com RVI e do R21 ao R40 referem-se a reclusas não inscritas neste regime.

\section{Apresentação e discussão dos resultados}

A adaptação à reclusão: dores de prisão (Sykes [1958] 2007) e estratégias de enfrentamento

O primeiro resultado que emerge das entrevistas às reclusas, estejam ou não inseridas no RVI, indica que a sua adaptação à reclusão foi algo psicologicamente perturbador. Este dado está patente nas afirmações que a maioria das entrevistadas fez sobre este período - «O começo foi difícil, muito difícil! Passava o dia fechada, a chorar [...] entrei em depressão» (R21) -, principalmente pela distância em relação aos filhos - «Muito má. Foi má, porque eu era uma mãe muito presente [...]. É os meus filhos. Eu não consigo aceitar. Roubaram-me tudo» (R7) - e está em consonância com a literatura que sugere que a adaptação à prisão é uma experiência stressante e que o seu ajustamento é crítico (Segurado e Magano 2014; Bender 2015; Kotova 2019).

Sykes ([1958] 2007) concetualizou cinco dores de prisão que visam representar as principais dificuldades e privações que os/as reclusos/as enfrentam durante o período de reclusão, designadamente: perda de autonomia e de segurança pessoal, privação de bens e serviços, de liberdade e de relações heterossexuais. A literatura mais recente sugere que, de modo geral, a experiência da reclusão é espe- 
cialmente dolorosa para a população reclusa por implicar o afastamento da sua família (Kotova 2019).

Especificamente, as dores de prisão que afetam mais significativamente as reclusas, e que têm sido evidenciadas em vários estudos como os fatores mais angustiantes (Casey-Acevedo e Bakken 2002; Granja 2017), são, além das já enunciadas por Sykes, a separação dos filhos e família e a falta de companheirismo. Também na nossa investigação, a relação com a família é considerada de grande importância para as reclusas e, face à experiência prisional, o afastamento desta, em particular dos filhos e a preocupação com estes - «Custa saber que a família está lá fora a passar necessidades e não poder fazer nada, custa não saber se um filho tem comida na mesa» (R1) - são sentidos como as maiores dores de prisão para todas as reclusas entrevistadas.

As restantes dores de prisão enunciadas pelas mulheres entrevistadas são a privação da liberdade e da autonomia, quer em relação às suas rotinas, quer na resolução dos seus problemas pessoais no exterior, o que está em consonância com o que tem vindo a ser indicado na literatura.

Pela análise de alguns dos discursos das mulheres reclusas entrevistadas, percebemos que esta dor de prisão relacionada com a privação da liberdade não é sentida apenas em termos de limitações físicas, isto é, não está apenas ligada com o impedimento de saída para o exterior, mas também com a privação daquilo que entendemos como uma liberdade sensitiva, na medida em que ultrapassa o isolamento e o afastamento físicos destas pessoas em relação à sociedade extramuros. O seguinte exemplo é bastante ilustrativo da expressão desta falta de liberdade sensitiva: «Sinto falta... de ver! Eu gosto de ser livre! Não só da forma física [...] aqui eu não vejo uma flor! Só muro, muro, muro! Isso me angustia tanto!» (R16).

Para lidarem com os constrangimentos decorrentes da entrada na prisão, as mulheres entrevistadas assumem uma modificação ou moldagem dos seus comportamentos - «Eu basicamente mudei em tudo. [...] aqui temos de aprender a lidar com todo o tipo de situações, uma pessoa aqui tem de crescer» (R4) - e adotam várias estratégias para lidar com a reclusão (Matos 2008; Gonçalves e Gonçalves 2012; Bender 2015). A estratégia mencionada pela maioria das reclusas passa por encontrar intramuros uma atividade que seja satisfatória, sendo a ocupação laboral a preferencial. Uma outra estratégia facilitadora da vivência da reclusão, mencionada por duas das entrevistadas, é a escrita, que foi apontada como um contributo para o seu bem-estar psicológico: «Como me entretenho na minha cela é a escrever poemas e versos. Às vezes quando estou zangada, pego num papel [...] escrevo o que me apetecer e depois rasgo! Fico aliviada!» (R8).

O apoio emocional da família é também encarado pelas entrevistadas como algo fundamental para o seu bem-estar psicológico, realçando a importância da segurança de que este suporte familiar se irá manter após a sua libertação —e.g., «A minha família tornou-se um pilar. Saber que tenho a minha família lá fora à minha espera é o mais importante de tudo» (R31). 


\section{O Regime de Visitas Íntimas: atitudes, vantagens e desvantagens}

Através dos meios de contacto com o exterior disponibilizados pelos estabelecimentos prisionais (Vieira, Saavedra, e Araújo 2015), os/as reclusos/as reconfiguram as suas relações afetivas, desafiando os significados tradicionalmente associados aos conceitos de distância e separação física (Granja 2017). Um dos meios de contacto, geralmente disponibilizados pelos estabelecimentos prisionais, é a visita íntima.

No presente estudo, as atitudes das entrevistadas perante a visita íntima, independentemente de usufruírem desta ou não, estão relacionadas com os significados que atribuem a estas visitas.

Por trás de uma atitude negativa relativamente ao RVI, tanto por quem passa pela experiência da visita íntima, como por aquelas que não tendo essa experiência se tentam colocar no papel das mulheres que o fazem, está a atribuição de um significado de perda de intimidade, a qual é transposta da esfera privada para o domínio público. Tal pensamento decorre quer da revista por desnudamento que antecede a visita íntima, e que lhes causa desconforto e as faz sentir-se humilhadas, quer dos comentários jocosos que são tecidos por outras reclusas. Por sua vez, as reclusas sem RVI, embora nunca tenham experienciado a ida à visita íntima, partilham desta opinião, como nos sugere o seguinte excerto: «Eu ouço-as dizer que se sentem extremamente constrangidas na revista e eu acho que também me sentiria. É uma humilhação» (R26). De acordo com um dos relatórios da Human Rights Law Centre (Ball e Walters 2017), a revista por desnudamento é invasiva e humilhante, traumatizante em determinadas situações, sugerindo que este tipo de procedimento, justificado como necessário para manter a segurança nos estabelecimentos prisionais, não é uma resposta razoável nem proporcional à consecução desse objetivo, sugerindo a procura de alternativas menos invasivas.

O campo das possibilidades de vivenciar a sexualidade na prisão mostra que a relação afetivo-sexual é redesenhada à luz da monitorização penal (Granja 2017). Parece que o espaço privado da sexualidade conjugal se transpõe para o espaço público da prisão, transformando a experiência de intimidade num acontecimento público (Lima 2006; Constant 2013). Como afirma uma das mulheres entrevistadas (R10), durante a sua visita íntima, ela não deixa de ter presente que a restante população prisional tem conhecimento da sua visita, o que interfere negativamente nessa experiência: «Vontade uma pessoa tem sempre, mas não estamos cem por cento à vontade, percebe? A gente sabe que uma cadeia inteira sabe que a gente está ali e para quê. Acho que devia de ser uma coisa mais reservada». Estas experiências sublinham o carácter altamente intrusivo das visitas íntimas, que redesenham a área mais privada de intimidade dos indivíduos e fazem colapsar os limites entre o público e o privado (Granja 2017).

As entrevistadas que têm uma atitude positiva em relação à visita íntima, quer usufruam ou não desta, atribuem-lhe um significado assente principalmente 
na vantagem deste tipo de visita por facilitar a manutenção do elo de conjugalidade, por permitir uma convivência mais duradoura e num contexto mais isolado com os companheiros, o que, por sua vez, de acordo com a sua perspetiva, permite evitar a infidelidade dos mesmos. Tal como defendem as entrevistadas de ambos os grupos, a ida à visita íntima contribui para a manutenção da estabilidade das relações e concorre para a diminuição da angústia associada ao medo do abandono.

Um outro resultado que surge das narrativas das mulheres entrevistadas de ambos os grupos relaciona-se com o facto de o apoio emocional proporcionado pelos companheiros às mulheres com RVI ser sentido por estas e percecionado pelas reclusas sem RVI como tendo mais valor do que a parte sexual que pode ocorrer durante a visita íntima, o que está em consonância com os resultados apresentados por Granja (2017). As mulheres colocam a gratificação sexual em segundo plano, quer quando a motivação principal para a adesão ao regime de visitas íntimas é a tentativa de evitarem a infidelidade dos companheiros, quer quando referiram valorizar o apoio emocional que recebem do companheiro durante a visita íntima em detrimento da relação sexual. Pensamos que tal se pode dever, primeiro, às próprias caraterísticas do contexto que levam as mulheres a desvalorizar o ato sexual, por não se sentirem completamente à vontade; segundo, o impacto da própria experiência da reclusão, na medida em que a falta de afeto e companheirismo é uma das grandes dificuldades sentidas pela maioria das entrevistadas, o que as leva a uma reconfiguração das suas prioridades, prevalecendo a dimensão afetiva sobre a dimensão sexual. Esta maior importância atribuída às questões emocionais, pode também refletir as dinâmicas subjacentes às relações sociais de género e à construção da identidade feminina, na qual as mulheres constroem a sua identidade nas relações de pertença, em particular nos papéis de mãe e esposa (Granja 2017), o que leva a que estas privilegiem a manutenção da família, e o papel da mulher na mesma, e desvalorizem as questões da sexualidade (Cordeiro 2017).

Em relação à influência das visitas íntimas sobre a sua vivência da reclusão, a maioria das reclusas entrevistadas afirma que esta é exercida quer sobre o seu estado emocional, quer sobre o seu comportamento, sendo que a maioria das reclusas relata que a sua participação no RVI favorece o seu bem-estar, facilitando a sua vivência da reclusão - «Dá-me força para continuar a seguir em frente. Acho que sem isso isto ia ser muito mais complicado» (R14). Neste sentido, a visita íntima funciona como uma atenuante da dor de prisão relacionada com a privação da liberdade para as reclusas inscritas neste regime, na medida em que, para a maioria delas, esta lhes proporciona uma sensação de escape à prisão, que lhes é facilitada pelas condições físicas do quarto de visita ao serem diferentes das características da restante área prisional. As visitas íntimas contrastam, assim, com as atividades rotineiras da reclusão e a exposição a que todos os intervenientes são submetidos durante as visitas prisionais regulares (Granja 2017). Como referiu uma das entrevistadas, estar no quarto da visita íntima transporta-a psicologicamente para o 
exterior pelas semelhanças físicas que este espaço tem com outros espaços do exterior da prisão e pelas diferenças relativamente ao ambiente institucional, ou, como referem Mancini et al., a visita «proporciona às mulheres um breve alívio da vida na prisão» $(2016,180)$, pelas condições físicas do local onde ocorre a visita.

Uma outra dor de prisão que é atenuada com a ida à visita, e que emerge do discurso das reclusas, é a que se relaciona com a separação dos filhos. No caso das reclusas com RVI, esta preocupação com os filhos acaba por ditar a dinâmica da visita íntima, na medida em que, a maioria deste grupo de reclusas, afirma que, das três horas de visita íntima, grande parte do tempo é passado a conversar acerca dos filhos do casal, o que lhes proporciona bem-estar emocional. Este tipo de visita contribui, assim, para diminuir a preocupação das reclusas acerca do bem-estar dos seus filhos, através da garantia de que estes estão a receber o apoio de que necessitam durante a sua ausência (Mancini et al. 2016).

Em termos comportamentais, a maioria das entrevistadas afirma que as visitas íntimas evitam o seu mau comportamento institucional, como nos explica a entrevistada R7: «Influencia. Porque isto, se não houvesse visita íntima isto havia muita porrada, muita porrada! A visita íntima faz-nos pensar duas vezes, porque a gente sabe que se vai ter um castigo podemos ficar sem a visita íntima». Assim, parece que, tal como sugerido por outros autores, a visita íntima não só diminui o isolamento social na prisão, aumentando o bem-estar psicológico da pessoa reclusa (De Claire e Dixon 2017; Ospina-Gómez e Bedoya-Gallego 2019), como também, ao permitir a manutenção dos laços com a família, funciona como um instrumento de controlo informal, podendo contribuir para desencorajar a sua má conduta institucional (Jiang e Winfree 2006).

Em suma, além de contribuírem para preservar laços afetivos entre cônjuges e outras pessoas significativas, as visitas íntimas aumentam o bem-estar psicológico das reclusas, com os benefícios que daí emergem para a disciplina e segurança nos estabelecimentos prisionais.

\section{Conclusões}

Nos últimos anos, os contextos penais têm vindo a tornar-se mais permeáveis ao exterior (Cunha 2014), criando mais e melhores condições para que as relações se mantenham na interface entre a prisão e o contexto externo, o que, por sua vez, facilita o processo de adaptação dos/as reclusos/as à sua nova conjuntura dentro do estabelecimento prisional.

À data das entrevistas, quando levadas a refletir sobre como decorreu a sua adaptação, a maioria das reclusas entrevistadas admitiu que a fase inicial do seu período de reclusão foi uma experiência psicologicamente dolorosa e o seu ajustamento crítico. É evidente nas entrevistas que a experiência da reclusão implica, de forma mais ou menos acentuada, a quebra nas relações sociais das reclusas de 
ambos os grupos, o que, face à sua clara valorização da esfera afetiva, é algo vivido com grande angústia por todas as entrevistadas.

A nossa investigação sugere que a dificuldade das reclusas em adaptar-se ao ambiente prisional está diretamente relacionada com a falta de apoio de outras pessoas significativas fora da prisão. Assim, o stress vivido na prisão é relatado como maioritariamente provocado pelas dores de prisão, as quais surgem associadas à falta de apoio social dos membros da família em geral e ao afastamento dos filhos em particular, dificultando a sua adaptação. Para lidar com estes constrangimentos e atenuar estas dores de prisão, as reclusas adotam várias estratégias, as quais passam por ter uma atividade satisfatória intramuros de modo a assumir novas rotinas. A obtenção de apoio emocional por parte de pessoas significativas, maioritariamente companheiros e filhos, assume-se nos discursos das reclusas como o maior proporcionador de bem-estar emocional, contrariando quer a solidão sentida no período de reclusão, quer o medo de serem abandonadas por estes e ficarem sozinhas após este período. Neste sentido, a visita dos companheiros permite atenuar não só a solidão sentida pelas reclusas, como também colmatar a carência emocional decorrente desta experiência (Cordeiro 2017). Assim, níveis mais baixos de suporte estão associados a níveis mais elevados de ansiedade, sugerindo que quanto maior os níveis de apoio social, menor a probabilidade dos / as reclusos/as virem a sofrer de sintomas de depressão, tal como relatado por Listwan et al. (2010). Neste sentido, a manutenção das relações previamente existentes, tais como as parentais, são de promover, não só pela atenuação dos potenciais efeitos nocivos da separação, mas também com vista à futura integração social (Vieira, Saavedra, e Araújo, 2015). Tal como nos sugere Granja (2017), emerge daqui a necessidade de (re)pensar criticamente o papel da família na esfera penal e de serem criados mecanismos adicionais que facilitem a preservação de laços na interface entre o mundo prisional e o exterior.

Quer as vantagens, quer as desvantagens atribuídas à visita íntima são coincidentes entre as entrevistadas de ambos os grupos, o que mostra que usufruir ou não do RVI não tem influência nas atitudes que ambos os grupos têm em relação às visitas íntimas. Ambos os grupos salientam a estabilidade familiar proporcionada pela visita como a maior vantagem deste regime e como principal desvantagem a perda de privacidade associada à ida para a visita. Granja, Cunha, e Machado (2012) defendem que as relações íntimas em conjugação com este controlo penal patenteiam a reconfiguração da intimidade e das suas dinâmicas afetivas e sexuais. A inibição da vivência da intimidade e da sexualidade levantam questões paradoxais no âmbito das políticas penitenciárias (Constant 2013). Por um lado, a crescente importância atribuída à manutenção dos laços familiares durante o cumprimento da pena de prisão tem conduzido ao crescimento de oportunidades de contactos entre casais nos contextos penais (Granja, Cunha e Machado 2014). Por outro, as limitações impostas aos contactos íntimos e sexuais na prisão continuam a repercutir-se nos sistemas penais atuais, limitando e res- 
tringindo as possibilidades dos casais de conservar os laços afetivos que os unem (Comfort et al. 2005).

Perante estes dados, podemos sugerir que a influência positiva que a visita íntima tem na adaptação e consequente vivência da reclusão das mulheres entrevistadas prende-se com o facto de, com este regime, ser proporcionado um espaço que possibilita à reclusa uma experiência de intimidade com o companheiro. Esta experiência de intimidade, ao ser percecionada por todas as reclusas como uma forma de manutenção do elo de conjugalidade, atenua a dor de prisão associada à perda de laços afetivos com quem lhes é mais próximo, o que, por sua vez, lhes proporciona um maior bem-estar no decurso da pena de prisão. Da mesma forma, para não perderem a vantagem da visita íntima, as reclusas evitam o mau comportamento, o que poderia contribuir para uma maior dificuldade da vivência prisional.

Com base nos resultados do nosso estudo, podemos sugerir que a ida da mulher à visita íntima, ao funcionar como um fator desencorajador do comportamento negativo e ao contribuir para o aumento do bem-estar geral da reclusa, exerce uma influência positiva na adaptação à prisão. Assim, esta relação entre o comportamento institucional e a possibilidade de autorização, ou não, das visitas íntimas acaba por ser também mais um instrumento de gestão penitenciária que o estabelecimento prisional tem ao seu dispor para manter a ordem. Neste sentido, o objetivo último das visitas íntimas seria criar nas reclusas uma motivação adicional e extrínseca para o seu bom comportamento. Isto é, o que leva as reclusas a autorregular o seu comportamento não é apenas a vontade intrínseca de ter bom comportamento, mas também o desejo de concretizar a visita íntima, pelos contributos positivos que esta tem sobre o seu bem-estar emocional. Assim, a visita íntima acaba por ser mais um mecanismo disciplinar para assegurar a boa conduta institucional.

As teorias a favor do isolamento e da separação com base no cumprimento das políticas e práticas de punição e segurança das prisões evoluíram gradualmente para a compreensão atual da importância da família e dos amigos na reabilitação da pessoa reclusa (Casey-Acevedo e Bakken 2002), bem como na definição das visitas como um programa de reabilitação que cria um sistema forte de suporte social proporcionado à população reclusa, com efeitos na sua reintegração na sociedade (Boman e Mowen 2017). Tendo isto em conta, esperamos que os resultados deste estudo possam concorrer para salientar as vantagens deste tipo de visitas para a vivência prisional das reclusas. De acordo com Pettus-Davis et al. (2018), o suporte social vivenciado durante a reclusão, no qual se enquadra o que é proporcionado pelas visitas dos companheiros, é um fator de proteção durante a reinserção das reclusas na sociedade, uma vez que lhes proporciona um sentimento de previsibilidade, estabilidade e pertença. Assim, ao demonstrar que, do ponto de vista da maioria das reclusas, o RVI é uma contribuição para o equilíbrio psicoafectivo e comportamental de quem dele usufrui durante o cumprimento da 
sua pena de privação da liberdade, a nossa investigação sugere que melhorar este regime pode ajudar a melhorar a vida de toda a comunidade prisional, bem como a qualidade da sua reinserção social.

Em suma, julgamos que a pertinência deste estudo tem a ver não apenas com as caraterísticas da amostra, uma amostra sobre a qual as investigações têm sido escassas, mas também com a importância de tentar compreender a forma como determinadas experiências na prisão influenciam o modo como as reclusas vivenciam a sua reclusão, pois consideramos que melhorar o ambiente correcional é um passo importante para uma reabilitação mais bem-sucedida.

\section{Referências bibliográficas}

Ball, Rachel, e Adrianne Walters. 2017. Total Control: Ending the routine strip searching of women in Victoria's prisons. Melbourne: Human Rights Law Centre. Disponível em https: //www.hrlc.org.au/reports/2017/12/5/report-total-control-ending-the-routine-strip-searching-of-women-in-victorias-prisons.

Bardin, Laurence. 2006. Análise de conteúdo. Traduzido por Luís Antero Reto e António Pinheiro. Lisboa: Edições 70.

Bender, Kimberly. 2015. «Exploring incarcerated women memorable messages and the effects of prison relationships on doing time.» Tese de doutoramento, Michigan State University.

Boman, John, e Thomas Mowen. 2017. «Building the ties that bind, breaking the ties that don't.» Criminology \& Public Policy 16 (3): 753-774. DOI: https://doi.org/10.1111/17459133.12307.

Casey-Acevedo, Karen, e Tim Bakken. 2002. «Visiting women in prison: Who visits and who cares.» Journal of Offender Rehabilitation 34 (3): 67-83. Disponível em https://doi. org/10.1300/J076v34n03_05.

Chen, Yu-Shu, Yung-Lien Lai, e Chien-Yang Lin. 2014. «The impact of prison adjustment among women offenders: A Taiwanese perspective.» The Prison Journal 94 (1): 7-29. DOI: https://doi.org/10.1177/0032885513512083.

Cochran, Joshua. 2012. «The ties that bind or the ties that break: Examining the relationship between visitation and prisoner misconduct.» Journal of Criminal Justice 40 (5): 433-440. DOI: https://doi.org/10.1016/j.jcrimjus.2012.06.001.

Comfort, Megan, Olga Grinstead, Kathleen McCartney, Philippe Bourgois, e Kelly Knight. 2005. ««You can't do nothing in this damn place!» Sex and intimacy among couples with an incarcerated male partner». Journal of Sex Research 42(1): 3-12. DOI: https:// doi.org/10.1080/00224490509552251

Constant, Chloé. 2013. «Sexe(s) derrière les barreaux: Inégalités d'accès à la visite intime et hétérogénéité des pratiques sexuelles», RITA - Revue Interdisciplinaire de Travaux sur les Amériques 6: 1-18. Disponível em http://www.revue-rita.com/notes-de-recherche6/ chloe-constant.html [Consultado em 11 de abril de 2020].

Cordeiro, Fabíola. 2017. «Criminalidade, gênero e sexualidade em uma penitenciária para mulheres no Brasil.» Trivium - Estudos Interdisciplinares 9 (1): 1-15. DOI: https://doi. org/10.18379/2176-4891.2017v1p.1. 
Cunha, Manuela Ivone. 1994. Malhas que a reclusão tece: Questões de identidade numa prisão feminina. Lisboa: Gabinete de Estudos Jurídico-Sociais do Centro de Estudos Judiciários.

Cunha, Manuela Ivone. 2002. Entre o bairro e a prisão: Tráfico e trajectos. Lisboa: Fim de Século.

Cunha, Manuela Ivone. 2014. «Categorias de diferença, crime e reclusão: glossários, estatísticas e experiências». In Género, Nacionalidade e Reclusão - Olhares cruzados sobre migrações e reclusão feminina em Portugal, organizado por Raquel Matos, 161-180. Porto: Universidade Católica.

D’Alessio, Stewart, Jamie Flexon, e Lisa Stolzenberg. 2013. «The effect of conjugal visitation on sexual violence in prison.» American Journal Of Criminal Justice 38 (1): 13-26. DOI: https://doi.org/10.1007/s12103-012-9155-5.

De Claire, Karen, e Louise Dixon. 2017. «The Effects of Prison Visits From Family Members on Prisoners' Well-Being, Prison Rule Breaking, and Recidivism: A Review of Research Since 1991». Trauma Violence \& Abuse 18 (2): 185-199. DOI: https://doi.org/ $10.1177 / 1524838015603209$.

Duarte, Vera, e Sílvia Gomes. 2015. A (des)construção de uma história única: Cruzando crime, género, classe social, etnia e nacionalidade. Revista Psiquiatria, Psicologia \& Justiça 8: 139-164. Disponível em: http://www.spppj.com/uploads/numero8_julho 2..5.pdf

Gonçalves, Leonel Cunha, e Rui Abrunhosa Gonçalves. 2012. «Agressividade, estilo de vida criminal e adaptação à prisão.» Psicologia USP 23 (3): 559-584. DOI: https://doi. org/10.1590/S0103-65642012005000013.

Granja, Rafaela. 2017. Para cá e para lá dos muros. Negociar relações familiares durante a reclusão. Porto: Afrontamento.

Granja, Rafaela, Manuela Ivone Cunha, e Helena Machado. 2012. «Intimidades em (des) conexão com a prisão: as relações amorosas de mulheres antes e durante a reclusão.» Comunicação apresentada no VII Congresso Português de Sociologia: Sociedade, Crise e Reconfigurações, junho 19 a 22 de 2012.

Granja, Rafaela, Manuela Ivone Cunha, e Helena Machado. 2014. «Sexuality, gender and confined bodies: Female prisoners experiences of intimate visits in a Portuguese prison». In Gender, sexuality and the body: Critical perspectives, organizado por Sofia Aboim e Pedro Vasconcelos, 70-80. Lisboa: Instituto de Ciências Sociais da Universidade de Lisboa. Disponível em https://hdl.handle.net/10451/11073 [Consultado em 11 de abril de 2020].

Jiang, Shanhe, e Thomas Winfree. 2006. «Social Support, Gender, and Inmate Adjustment to Prison Life: Insights from a National Sample.» The Prison Journal 86 (1): 32-55. DOI: https://doi.org/10.1177/0032885505283876.

Kotova, Anna. 2019. «Time...lost time: Exploring how partners of long-term prisoners experience the temporal pains of imprisonment.» Time $\mathcal{E}$ Society 28 (2): 478-498 DOI: https://doi.org/10.1177/0961463X18763688

Lima, Márcia. 2006. «Da visita íntima à intimidade da visita: a mulher no sistema prisional.» Tese de doutoramento, Faculdade de Saúde Pública de São Paulo.

Listwan, Shelley Johnson, Mark Colvin, Dena Hanley, e Daniel Flannery. 2010. «Victimization, social support, and psychological well-being: A study of recently released prisoners.» Criminal Justice and Behavior 37 (10): 1140-1159. DOI: https://doi.org/ $10.1177 / 0093854810376338$.

Mancini, Christina, Thomas Baker, Karla Sainju, Kristin Golden, Laura Bedard, e Marc Gertz. 2016. «Examining External Support Received in Prison and Concerns About 
Reentry Among Incarcerated Women.» Feminist Criminology 11 (2): 163-190 DOI: https://doi.org/10.1177/1557085115579483.

Matos, Raquel. 2008. Vidas raras de mulheres comuns. Percursos de vida, significações do crime e construção da identidade em jovens reclusas. Coimbra: Almedina.

Matos, Raquel, e Carla Machado. 2007. «Reclusão e laços sociais: discursos no feminino.» Análise Social 42 (185): 1041-1054. JSTOR: https://www.jstor.org/stable/41012765.

Mears, Daniel, Joshua Cochran, Sonja Siennick, e William Bales. 2012. «Prison Visitation and Recidivism.» Justice Quarterly 29 (6): 888-918. DOI: https://doi.org/10.1080/07418825. 2011.583932.

Melo, Sara de Oliveira. 2013. «O impacto da reclusão na esfera familiar da vida dos indivíduos encarcerados.» Dissertação de mestrado, Faculdade de Psicologia e Ciências da Educação da Universidade do Porto. Disponível em https://sigarra.up.pt/ffup/pt/ pub_geral.pub_view?pi_pub_base_id=252844.

Ospina-Gómez, Yésica, e Diana Marcela Bedoya-Gallego. 2019. «Efectos psicológicos generados tras la ruptura de los lazos con el grupo primário de apoyo debido al fenómeno de prisionalización.» Interdisciplinaria: Revista de Psicología y Ciencias Afines 36 (1): 171185 DOI: https://doi.org/10.16888/interd.2019.36.1.12.

Pettus-Davis, Carrie, Christopher A. Veeh, Maxine Davis, e Stephen Tripodi. 2018. «Gender differences in experiences of social support among men and women releasing from prison.» Journal of Social and Personal Relationships 35 (9): 1161-1182 DOI: https://doi. org $/ 10.1177 / 0265407517705492$.

Segurado, Nuno, e Olga Magano. 2014. «Mulheres ciganas, criminalidade e adaptação ao meio prisional.» Sociologia, Revista da Faculdade de Letras da Universidade do Porto. Número temático - Ciganos na Península Ibérica e Brasil: estudos e políticas sociais, 97-115. Disponível em http://www.scielo.mec.pt/pdf/soc/ntematico4/ntematico4 a07.pdf

Silva, António Ricardo. 2016. «Homens 'verdadeiros' não fazem sexo na prisão: Vivência da sexualidade na reclusão.» Dissertação de mestrado, Faculdade de Psicologia e Ciências da Educação da Universidade do Porto.

Smart, Carol. 2008. "Criminological theory: its ideology and implications concerning women.» In Gender and crime: a reader, editado por Karen Evans e Janet Jamieson, 5-15. Berkshire: Open University Press.

Steiner, Benjamin, e John Wooldredge. 2009. «Individual and environmental effects on assaults and nonviolent rule breaking by women in prison.» Journal of Research in Crime and Delinquency 46 (4): 437-467. DOI: https: //doi.org/10.1177/0022427809341936.

Sykes, Gresham. (1958) 2007. The society of captives: A study in a maximum security prison. Princeton: Princeton University Press.

Turanovic, Jillian, e Melinda Tasca. 2019. «Inmates' Experiences with Prison Visitation.» Justice Quarterly 36 (2): 287-322 DOI: https://doi.org/10.1080/07418825.2017.1385826.

Vieira, Catarina, Luísa Saavedra, e Alexandra M. Araújo. 2015. «Preservando a relação com os/as descendentes menores: padrões de comunicação na maternidade e paternidade em reclusão.» Ex aequo 32: 141-154. DOI: https://doi:10.22355/exaequo.2015.32.09.

Visher, Christy, e Daniel O'Connell. 2012. «Incarceration and inmates' self-perceptions about returning home.» Journal of Criminal Justice 40 (5): 386-393. DOI: https://doi. org/10.1016/j.jcrimjus.2012.06.007. 
Rita Pinto. Mestre em Psicologia da Justiça, pela Universidade do Porto. Autora da Dissertação de Mestrado «A Influência das Visitas Íntimas na Vivência da Reclusão Feminina», com a classificação final de 19 valores, dando origem a participações em seminários e congressos. Das suas experiências profissionais, destaca-se o trabalho em Inglaterra com jovens em risco. Os seus interesses de investigação ligam-se com o género e a exclusão social, colaborando em projetos de investigação nesta área.

Endereço eletrónico: psi.ritapinto@gmail.com

Alexandra Oliveira. Professora Auxiliar da Universidade do Porto, onde se doutorou, na Faculdade de Psicologia e de Ciências da Educação, sendo subdiretora de Departamento e diretora do Mestrado Integrado em Psicologia. Os seus interesses de investigação ligam-se com o género, a sexualidade e o desvio e controlo social, tendo vindo a dedicar-se particularmente ao estudo da prostituição. É autora de diversas publicações nacionais e internacionais e os seus trabalhos foram premiados.

Endereço eletrónico: oliveira@fpce.up.pt

Artigo recebido a 27 de dezembro de 2019 e aprovado para publicação em 6 de abril de 2020. 